\title{
The Impact of Flexible Strategy on Resource Allocation - Case Study of the Energy Enterprises
}

\author{
Song Zhuo ${ }^{1}$ Sha Yuheng ${ }^{1}$ Deng Chunyu ${ }^{2}$ Zhang Yuxi ${ }^{2 *}$ Wang Xue ${ }^{2}$
}

\author{
${ }^{1}$ State Grid Corporation of China, Beijing 100031,China \\ ${ }^{2}$ China Electric Power Research Institute, Beijing 100192, China \\ *Corresponding author. Email: zhangyuxi@epri.sgcc.com.cn
}

\begin{abstract}
With the deepening of globalization, changes in the internal and external environment of an enterprise are accelerating. How to use internal and external resources of an enterprise to cope with environmental uncertainty and adjust the development strategy of the enterprise in a timely manner has become challenges for enterprises. This study observes the resource allocation under the external market regulation of Huaneng Power Intl Inc. and EDF from the perspective of strategic flexibility. By comparing the case studies, we found that when facing with market regulation, enterprises can allocate resources in the three aspects. It could allocate the resource in the supply chain, mergers and acquisitions, and technological change to achieve their competitiveness in an uncertain environment. In short, in facing with uncertain environments, the process of resource allocation is a key link in achieving strategic flexibility.
\end{abstract}

Keywords: market regulation, flexible strategy, resource allocation

\section{NTRODUCTION}

With the deepening of globalization, the internal and external environment of an enterprise is more difficult to predict. How to respond to environmental uncertainty through the existing internal and external resources of the enterprise and adjust the development strategy of the enterprise in a timely manner is the source of the core competitiveness of the enterprise. Resource allocation is an important part of the enterprise's strategic transformation process. A large number of theories measure the enterprise's strategic transformation from the dimension of resource allocation. These theories believe that the allocation of enterprise's original resources is redistributed and integrated through new activities to obtain new resource allocation. It is useful to achieve strategic transformation. Existing theories believe that resource allocation is mainly to protect and restrict the strategic transformation of enterprises. These resources include human resource, product material, reputation, finance, and so on. The stability of these resource is the original capital of the enterprise, which is the basis for the survival and development of the enterprise. The resource supply and sustainability are fundamental to ensure the strategic transformation of the enterprise. Therefore, resource allocation plays a fundamental role in the strategic transformation of the enterprise. Meanwhile the amount of resources also restricts the rate and direction of the strategic transformation of the enterprise. Evans(2016) proposed that under a new environment, the efficient and valuable resource allocation accumulated by enterprise organizations in the past is likely to create a "capability trap" for the enterprise itself. The resource preventing the enterprise from carrying out necessary organizational learning and organization capabilities improvements such as innovation. These traps will also cause "vortexes", which will reduce the company's perception of changes to adopt to change of the external environment. It also hides the information search behavior of the company. Eventually, managers will make slower decisions, slower responses when facing complex environments. Comebe et al. (2019) point out that the more advantages of resource allocation enterprise have, the more rigidity the core competence transformation. The resource cannot effectively adapt to the new environment due the process dependence of the resource allocation. Teece and Pisan (1997) and others believe that high-quality enterprises should have the ability to integrate, establish, and reallocate internal and external resources. If an enterprise wants to maintain a lasting competitive advantage and obtain high performance in a turbulent and complex environment, it must ensure the dynamic nature of its competitive ability, and this ability to respond in a timely manner comes from strategic flexibility.

The Scholars have different views about strategic flexibility. Ansoff (1965)[1] proposed "strategic flexibility" based on the idea of catastrophe management firstly. The author believed that flexibility is the main indicator used by companies to resist risks brought by environmental changes. Based on contingency theory, Dyer and Singh(1998)[3] point out that enterprises should first divide all resources to form strategic strategies, and improve the adaptability of enterprises to the environment. At this process, the enterprise should choose the best decision that is more adaptable to future environmental changes. Worrenn, Moore, and Cardona (2002)[8] pointed out that resource flexibility in resource allocation and 
product design can prompt organizations to use new technologies on diversified products. At present, scholars have made great progress in related researches, but there are also lots of questions should be further explored. Most of the existing researches are based on resource-based theory. These researches focusing on maximizing the use of resource effects, responding to environmental changes through resource allocation, emphasizing strategic flexibility to passively adapt to changes in the organizational environment. These researches are ignoring the active characteristics of strategic flexibility, that is the company actively allocate reasonable resources to adapt to strategic changes under pressure. On the other hand, the world is under the context of green transformation, the environmental regulations are changes rapidly and unpredictability. The energy enterprise strategies will also be impacted by the environment. However, the existing research does not analyze how companies respond to the influence of environmental regulations, and better play the role of strategic flexibility in corporate transformation. There is lack of better strategic flexibility for companies with strategic flexibility. The allocation of resources has achieved rapid development. In order to fill these theoretical gaps, this study takes Huaneng Power Intl Inc. and EDF as examples to analyzes the mechanism of internal and external environmental factors' impact on enterprise transformation based on strategic flexibility theory. This research also ultimately provides a scientific and valuable reference for enterprise resource allocation.

\section{THEORETICAL REVIEW}

\subsection{Resource allocation}

Resource allocation is a more prominent element in the process of enterprise strategic transformation. There are many theories to measure enterprise strategic transformation from the dimension of resource allocation. It is believed that the strategic transformation is derive from the resource reallocation and integration through the firms' activities and resource allocation process. Resourcebased view theory believes that an enterprise is regarded as a collection of heterogeneous resources. This unique heterogeneous resource can obtain economic rent for the enterprise, so these heterogeneous resources can be used in the process of enterprise transformation. Resources to gain new competitiveness from new combinations. Dai et al. (1997)[4] based on the theory of resource dependence and the view of resource foundation, pointed out that enterprises use, maintain and build their own advantages in resource allocation, through strategic transformation. To achieve a new resource allocation, this process is also based on the difference of resource allocation. This process is also a survival process of the fittest. The smaller the gap, the easier for the firm's strategic transformation. The larger the gap, the more difficult to change the firm's strategy. When the enterprise continues to narrow the gap with the planned target resource allocation, the enterprise is in the process of gradual strategic transformation.

The restrictive effect of resource allocation on the enterprise's strategic transformation is reflected in enterprises with resource advantages, especially in energy enterprises. When facing with drastically environmental changes, a company with a strong resource allocation advantage deter its' development. This is because the company's own resource allocation advantage has a path dependence and this weaken the enterprise's necessary learning ability, innovation ability, and cognitive ability to adopt the external environment. These abilities have been restricted by the former advantages. Such theories are mainly based on theoretical perspectives such as organizational inertia theory, organizational learning theory, organizational legitimacy theory, organizational innovation theory, and organizational surplus theory. In the process of enterprise transformation, the efficient and valuable resource allocation form accumulated by the enterprise organization in the past is likely to make the company dependent on the path. In the process of collecting information, enterprises are also more confined to the original information channels, and their ability to respond to changes in the external environment is weaker, which ultimately leads to weaker competitiveness of the enterprise. The resource allocation capability of an enterprise may become a strategic rigidity that hinders its development in the process of changes in the external environment.

\subsection{Strategic flexibility}

Since Ansoff (1965)[1] proposed the concept of strategic flexibility, different scholars have enriched their connotations. The connotation of strategic flexibility can be divided into three categories: the first category regards strategic flexibility as the organization uses less resources, costs, and time to respond to external dynamic changes (Aggarwal, 1997). The second category believes that strategic flexibility is an adaptability of an enterprise, and is the ability of an organization to integrate internal and external strategies to cope with a dynamically changing environment. The third category is to understand the strategic flexibility of an organization from the perspective of options. This view integrates Ansoff's (1965)[1] option theory, and regards strategic flexibility as strategic options used by enterprises in dynamic environments (Bowman Hurry 1993). Zhang (2001) further divided the strategic flexibility into customers, suppliers, technology and instability of competition on the basis of their predecessors. Cohen and Levinthal (1990)[5] pointed out that the environmental impact of an enterprise refers to a series of indicators of the dynamic changes of the internal and external environment. Baranova and Meadows(2017)[6] believes that the unpredictability of the organizational environment will have an important impact on corporate strategic choices and market strategies. Galbreath (2014)[7] is proposed the influence from the perspective of environmental causes. He believes that the alternating 
speed of technology and market will inevitably affect the dynamics of the environment and produce a first-mover advantage.

In the face of a dynamically changing economic environment, companies have to upgrade their increasingly changing external environment, so strategic flexibility is necessary. In the process of change, enterprises have been concerned about strategic resource allocation in order to better adapt to environmental surprise resource allocation. Most scholars divide strategic flexibility into two dimensions. Resource flexibility refers to the resources that an enterprise can use to achieve the ability to change the enterprise's operating strategy at a lower cost. This ability can improve the adaptability of the enterprise in a turbulent environment; Easier customer service issues, achieve high-growth corporate performance and obtain sustainable competitiveness. In addition, the external environment is constantly changing, and companies must have sufficient flexibility to quickly organize the various resources they own in a fast and efficient manner, or to increase the conversion rate of resource utilization to reduce turbulent changes in the external environment Risks and uncertainties. Capability flexibility is the ability of an enterprise to find and integrate new resources in the changing external environment, and then allocate various resources to maximize the use of resources. The resource structure of an enterprise will change due to the emergence of new resources, so the ability to rationally allocate new resources, that is, flexibility will also change. However, this change in ability flexibility is a gradual change. It is an enterprise that has never had the ability to change. This ability is that new resources can better affect the enterprise and achieve high performance.

\section{RESEARCH METHODS}

\subsection{Case study}

This article uses an exploratory dual case study method to explore how companies use internal resource allocation to achieve corporate development strategies in the context of global green sustainable development, and how to use internal resource allocation to achieve corporate development strategies. The purpose of this article is to study the internal resource allocation of the enterprise based on the strategic flexibility of the enterprise, which belongs to the discussion of the operation mechanism. At the same time, this article discusses the impact of environmental changes on enterprise resource allocation from the perspective of strategic flexibility, therefore the case study method can better reflect the entire dynamic change process. Compared to single-case studies, dualcase studies allow cross-case comparative analysis, which can observe activities in multiple situations in a deeper level, and thus provide a more comprehensive description and clear explanation for the construction of the theory, which can improve the contribution of this article.

Table 1 Descriptive statistics of case data sources

\begin{tabular}{|c|c|c|c|c|c|c|c|}
\hline \multirow[b]{2}{*}{$\begin{array}{l}\text { Profile } \\
\text { name }\end{array}$} & \multicolumn{4}{|c|}{ First-hand materials } & \multicolumn{3}{|c|}{ Second-hand materials } \\
\hline & $\begin{array}{l}\text { Interview } \\
\text { duration } \\
\text { (minutes) }\end{array}$ & $\begin{array}{l}\text { Interview } \\
\text { word count }\end{array}$ & $\begin{array}{l}\text { Number of } \\
\text { interviewees }\end{array}$ & Interviewee & $\begin{array}{c}\text { Company } \\
\text { website, media } \\
\text { reports, public } \\
\text { accounts, online } \\
\text { reports }\end{array}$ & $\begin{array}{c}\text { Corporate } \\
\text { financial } \\
\text { report }\end{array}$ & references \\
\hline $\begin{array}{l}\text { Huaneng } \\
\text { Power Intl } \\
\text { Inc. }\end{array}$ & 220 & 35000 & 35 & $\begin{array}{l}\text { New business } \\
\text { customers, } \\
\text { original business } \\
\text { customers } \\
\text { (insurance, } \\
\text { banks), staff, } \\
\text { managers }\end{array}$ & 110 & 80 & 120 \\
\hline EDF & 210 & 36000 & 21 & $\begin{array}{l}\text { Middle leaders } \\
\text { and employees }\end{array}$ & 90 & 100 & 110 \\
\hline
\end{tabular}

\subsection{Selection of samples}

In the case study, selecting representative cases through theoretical sampling can achieve in-depth study of the cases, and then find its theoretical significance. According to the principle of theoretical sampling, this paper selects Huaneng Power Intl Inc. and French EDF (Electronic De France) as the analysis Object. The reasons for selecting the case are as follows: the representativeness of the case. Huaneng Power Intl Inc. and EDF are representative companies of energy in China and France, and have a large market share in their respective markets. At the same time, the two companies are under the influence of changes in the external environment and are in the stage of strategic transformation. However, the two companies have different strategies when faced with changes in the external environment, so it is a suitable case to choose these two companies. Regarding the availability of data, 
Huaneng Power Intl Inc. and French Electric Power Company, as large enterprises, have richer data information and higher credibility, and can improve the reliability and validity of related research from sample selection.

\subsection{Data source}

In order to ensure the reliability and validity of the case study, this paper adopts the method that primary data and secondary data want to combine to collect data. In terms of first-hand data acquisition, this article mainly takes the form of interviews to better study the development of the group. The targets of the interviews are mainly the managers and employees of the two companies. This article conducted interviews on 56 relevant persons through interviews. In terms of second-hand data, about 200 related materials are mainly obtained through the company's website, media reports, and online reports. The company's website obtains about 180 financial reports including the company's annual report, quarterly report and other related materials. Search about 230 relevant journals or reviews of the company through the database and case database, and systematically analyze these materials.

\section{THE FINDING OF CASES}

\subsection{Reasonable supply chain resource allocation}

The enterprise's flexible strategy improves the enterprise's ability to respond to external rules and allocate resources in different markets. Flexible strategies can reduce the impact of environmental regulations, rationally configure the supply chain, and reduce external shocks. In order to coordinate with the strategic transformation, Huaneng Power Intl Inc. has gradually adapted to the strategic development in the process of resource allocation, and has allocated a lot of resources in green development. With the strategic transformation in recent years, the proportion of thermal power in investment has become smaller and smaller, since 2011, the proportion of investment capital expenditure of thermal power in total capital expenditure has become smaller and smaller. The proportion of investment capital expenditures of thermal power in total capital expenditures has dropped from $70.9 \%$ in 2010 to $11.78 \%$. The proportion of hydropower investment capital expenditures to total capital expenditures has always been at a relatively low ratio. In 2012, the highest proportion was only $3.12 \%$ of all capital expenditures. After reaching its peak in 2012, it showed a downward trend year by year, accounting for only $0.06 \%$ in 2019 . Thanks to the support of policies in recent years, the company's investment in green energy has gradually increased, and investment in wind power and photovoltaic projects has shown a trend of increasing year by year. With the implementation of the Group's green energy strategy, Huaneng Power Intl Inc. has increased its investment in wind power projects. Since 2015 , the proportion of wind power projects in total capital expenditure has soared from $23.65 \%$ to $67.64 \%$ in 2019 . Wind power has become the absolute main force of the company's investment.

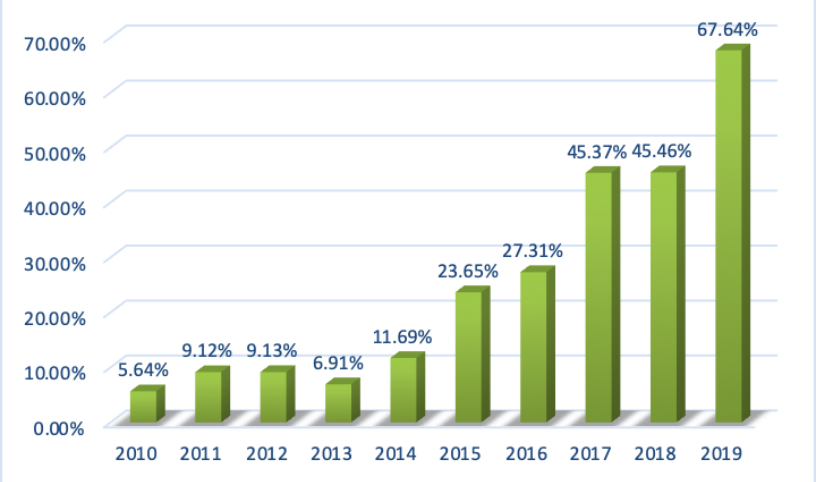

Figure 1 The proportion of wind power capital expenditures to total capital expenditures from 2010 to 2019

In terms of renewable energy. EDF continuously adjusts its energy strategy and invests in the continuous increase of the total installed capacity of renewable energy (see Figure 2 for details). Since the total installed capacity of renewable energy in 2011 was $20.4 \mathrm{GW}$, the total installed capacity of renewable energy reached $31.1 \mathrm{GW}$ in 2018 , an increase of $52.45 \%$. The share of available energy in different years is also constantly changing (see Figure 3 for details). In recent years, the year when the total installed capacity of renewable energy accounted for the smallest total installed capacity was 2012 . This proportion was $19.28 \%$. After 2012, the proportion of renewable energy installed capacity in the total installed capacity has increased year by year. This number has reached $24.58 \%$ by 2018 (see Figure 3). At the same time, in order to better optimize the supply chain, EDF continued to shut down domestic nuclear reactors (see Figure 4).

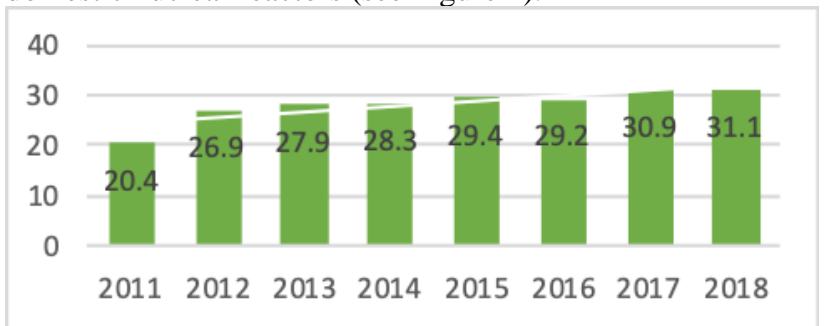

Figure 2 2011-2018 Group's total installed capacity of renewable energy changes (unit: GW) 


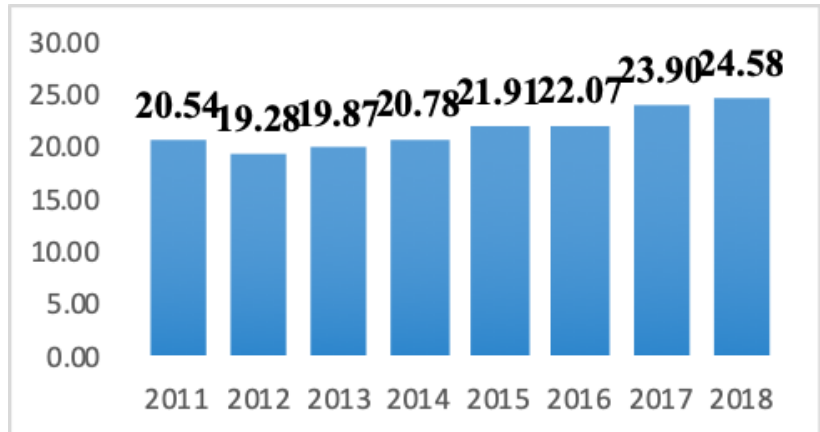

Figure 3 2011-2018 Group's total renewable energy installed capacity as a percentage of total installed capacity (unit:\%)

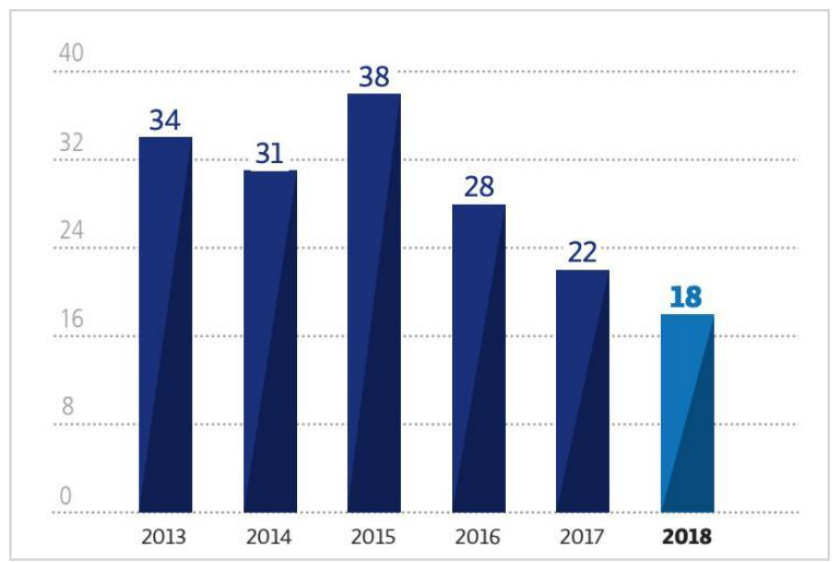

Figure 4 EDF nuclear reactor closures since 2013 (Unit: Block)

\section{2. $M \& A$ to gain more market share}

The flexible strategy improves the ability to capture market changes, find more potential companies, acquire more market share through mergers and acquisitions, and reduce policy impact. In order to reduce the increase in environmental requirements in the domestic market and the EU market, EDF conducted a total of $30 \mathrm{M} \& \mathrm{~A}$ transactions from 2009 to early 2020 (see Figure 5), with a maximum of 4 transactions in 2009 and 3 transactions in 2019. Geographically, M \& A transactions are also more diversified, with 4 acquisitions in Belgium, 3 in Poland, and the most acquisitions in Brazil, reaching 8 transactions. These acquisitions are more focused on the renewable energy field, and constantly allocate resources in accordance with strategic planning.
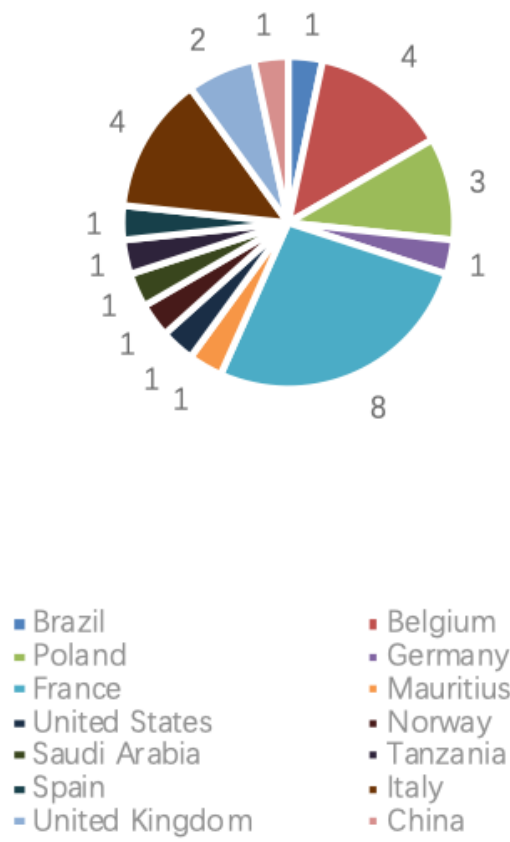

Figure 5 Regional distribution of acquisitions by EDF in 2009-2020

In response to environmental regulations, Huaneng Power Intl Inc. implemented overseas mergers and acquisitions. In 2008, the company's wholly-owned subsidiary in Singapore, Sino-Singapore Power Co., Ltd. and Temasek Singapore completed the equity delivery of Singapore Tuas Energy Co., Ltd. (Tusse Energy). So far, Huaneng Group holds $100 \%$ equity of Tuas Energy. Through the acquisition of Tuas Energy, Huaneng Group not only owns all Tuas Energy 's power generation assets, but also becomes an important participant in Singapore 's power generation and electricity retail markets. Through this transaction, Huaneng Group owns more than $25 \%$ of the Singapore electricity market. In 2013, Tuas Energy Company invested in the construction of a natural gas combined cycle unit after shutting down a 600,000kilowatt fuel unit, with an installed capacity of 406,000 kilowatts. The commissioning of Tuas Energy's Unit 5 will further consolidate the company's competitive position in the Singapore power generation market. In terms of equity investment, the company invests in equity every year. Equity investment also differs according to different years. In recent years, equity investment expenditures in 2012 were 1.5 billion yuan. From the later period to 2018, the equity investment amount was less than 1 billion, 2.76 billion in 2016, 3.25 billion in 2017, and 46.4 in 2018 . Billion (see specific figure). In the process of resource allocation, equity investment has always played an important role. Different investments are made in accordance with different development periods of the strategy. 


\section{Equity investment}

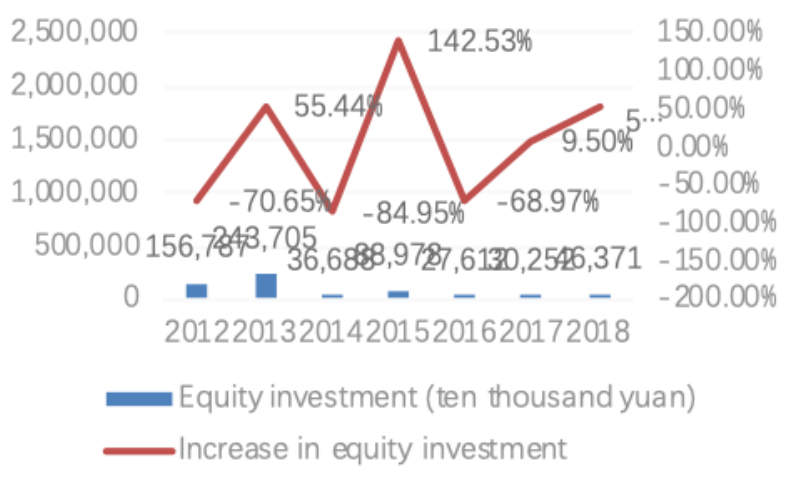

Figure 6 The company's equity investment finance and growth rate from 2012 to 2018

\subsection{Continuous technological changes}

Flexible strategies can strengthen enterprise innovation, better carry out technological innovation, and improve competitiveness. From 2004 to 2018, Huaneng Power Intl Inc. Thermal Power's low-carbon governance investment totaled over 100 billion yuan, and several projects have achieved impressive results. From the purchase of desulfurization and emission reduction devices of thermal power units, to the construction of ultra-supercritical units, to the major breakthroughs in the coal power technology of Tianjin IGCC power station, Huaneng Power Intl Inc. has reached the forefront of the industry in the development of low-carbon thermal power in China. In October 2005, the second-phase project of Shantou Power Plant expanded and expanded a 600,000-kilowatt domestically produced supercritical steam turbine generator set, which was successfully put into operation, with an investment of 1.087 billion yuan. In the secondphase project of Shantou Power Plant, Huaneng Power Intl Inc. has built generator sets equipped with environmental protection projects such as desulfurization devices, highefficiency dust removal devices, and sewage treatment devices. standard. In 2008, the third phase of the Shang'an Power Plant cost 2.607 billion yuan to install $2 \times 62$ million supercritical air-cooled generating units and put them into operation. In 2013, China's first coal gasification combined cycle power plant-Tianjin IGCC Demonstration Power Plant successfully entered the operational stage, which marked a milestone and major breakthrough in China's clean coal power generation technology. In 2014, Huaneng Power Intl Inc. Changxing Power Plant, China's first highefficiency ultra-supercritical coal-fired power plant, invested in the construction of two $660,000-\mathrm{kw}$ highefficiency ultra-supercritical coal-fired generating units that were put into operation in December of that year. The power plant uses the world's first, advanced concrete fully enclosed honeycomb cluster coal bunker. After the unit is put into operation and production, it is in good use, and various economic and environmental indicators have not only reached the standard value, even exceeded the design value.

In line with the Group's development strategy, EDF R \& D according to its own business sector in March 2016, EDF's new R \& D training center in the Sacre region was opened and put into use. For France Electric, three major strategic pillars have been identified within the institute: first, to develop renewable energy, consolidate and develop competitive low-carbon power generation technologies. Second, it is competing for French local and global energy systems and preparing for the next generation of power systems. Third, focus on users and local user groups, develop and test new energy service solutions for users. In order to grasp the future development trend of hydrogen energy, in June 2018, EDF invested 16 million euros (18 million US dollars) to acquire a $21.7 \%$ stake in McPhy, a leading supplier of hydrogen production, storage and distribution equipment. McPhy was founded in 2008, the company provides a full range of hydrogen solutions, including electrolyzes, hydrogenation stations and storage facilities. The company focuses research and innovation on being able to produce and provide hundreds or even thousands of kilograms of low-hydrocarbon solutions needed every day, and has three development, engineering and production centers in Europe (France, Italy, Germany) Its international subsidiaries provide extensive commercial coverage for its innovative hydrogen solutions.

\subsection{Reasonable resource allocation mechanism under strategic flexibility}

In the face of the dynamic external environment, enterprises with strategic flexibility can make better use of their own resources and constantly allocate resources in different ways to better improve their own competitiveness In the process of changes in the external environment, companies with strategic flexibility can better perceive changes in the environment, gradually allocate resources to supply chain enterprises that adapt to changes in the external environment, reduce the allocation in other supply chains, and impact the enterprises drop to lowest. In terms of innovation, in the face of impact, companies can better find the direction, continue to carry out technological innovation, and at the same time create new business directions under the guidance of innovation. Enterprises with strategic flexibility are more capable of catching market changes, looking for more potential companies, acquiring more market share through mergers and acquisitions, and reducing policy impact. In short, enterprises with strategic flexibility can better respond to changes in market regulations, and constantly adjust resource allocation to improve their core competitiveness. Resource allocation capabilities play a crucial role in this process. 
to implement strategy from the resource allocation

\section{COUNTERMEASURES AND SUGGESTIONS}

(1) Strengthen the ability of resource allocation in the supply chain

In the face of changes in market regulations, enterprises must constantly find new market positions, adjust resource allocation in different supply chains in real time, and transform the resource allocation capabilities of the supply chain into market adaptability. In the past, companies placed too much emphasis on the stability of the supply chain, which was not conducive to companies adapting to market changes. In the face of market changes, although the stability of the supply chain can reduce the risk of enterprise production, such stability constrains the development of the enterprise itself. Therefore, in the face of market changes, enterprises should facilitate strategic flexibility to continuously allocate resources in different supply chains to better respond to external risks.

\section{(2) Strengthen the role of $R \& D$}

In the face of changes in market regulations, enterprises must constantly improve existing technologies and develop new businesses on the basis of promoting the advancement of existing technologies. The resource allocation that matches the strategic flexibility to respond to market changes should also continue to invest in research and development, and achieve the purpose of improving competitiveness through the innovation of original technologies. At the same time, R \& D should also be continuously invested in the development of new technologies in order to find better alternatives to new products, so that enterprises can continue to operate.

\section{(3) Emphasize the role of mergers and acquisitions}

In the face of changes in market regulations, strategic flexibility can encourage companies to better understand changes in the market. During this process, companies continue to choose new markets and partners. In the process of resource allocation, consideration should also be given to quickly acquiring the market and technology of partners through mergers and acquisitions to achieve the purpose of entering new markets. At the same time, mergers and acquisitions can also serve as a means for companies to quickly gain competitive advantage in the target market. Through mergers and acquisitions to expand the competitiveness of enterprises in the target market, to avoid the risks caused by changes in market regulations.

\section{CONCLUSION}

After focus on the mechanism of the resource allocation of this two firms, we find it is the flexible strategy is benefit for the resource allocation especially when the environment drastically changes. This research is contribute to the prior from two aspects. First, we find three different mechanism to allocation when facing with emerging market. This is contribute to the flexible strategy which could use to mitigate environment risks. Second, we also contribute to the management researches which is focus much on the outcome of strategy and ignore process perspective. In all, we contribute prior research by construct the frame of resource allocation.

\section{ACKNOWLEDGMENT}

This paper is sponsored by State Grid Science and Technology Project (ID: 1300-201957273A-0-0-00) .

\section{REFERENCES}

[1] Ansoff, H.L, Corporate Strategy, McGraw Hill, New York, 1965

[2] Combe, I. A., Rudd, J. M., Leeflang, P. S. H. and Greenley, G. E. (2012). Antecedents to strategic flexibility management cognition, firm resources and strategic options. European Journal of Marketing, 46, 1320-39.

[3] Dyer, J. H. and Singh, H. (1998). The relational view: Cooperative strategy and sources of interorganizational competitive advantage'. Academy of Management Review, 23, 660-79.

[4] Dai, Y., Du, K., Byun, G. and Zhu, X. (2017). Ambidexterity in new ventures: The impact of newprod- uct development alliances and transactive memory systems. Journal of Business Research, 75, 7785.

[5] Cohen, W. M. and Levinthal, D. A. (1990). Absorptive capacity: A new perspective on learning and innovation'. Administrative Science Quarterly, 35, 12852.

[6] Baranova, P., \& Meadows, M. (2017). Engaging with environmental stake- holders: Routes to building environmental capabilities in the context of the lowcarbon economy. Business Ethics: A European Review, 26(2), 112-129.

[7] Galbreath, J. (2014). Climate change response: Evidence from the Margaret River wine region of Australia. Business Strategy and the Environment, 23(2), 89-104.

[8] Worrenn, Moore, Cardona. Modularity, strategic flexibility, and firm performance: a study of the home appliance industry [J]. Strategic Management Journal, 2002, 23 (12): 1123-1140. 